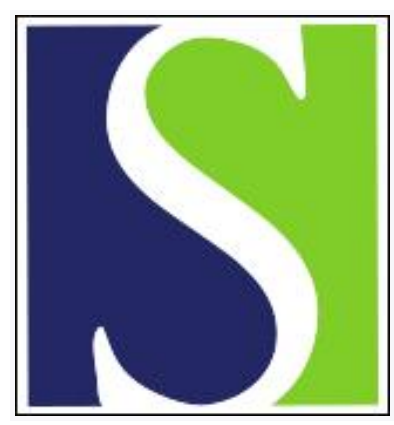

Scand J Work Environ Health 2011;37(1):45-53

https://doi.org/10.5271/sjweh.3089

Published online: 13 Sep 2010, Issue date: Jan 2011

Does stress at work make you gain weight? A two-year longitudinal study

by Berset M, Semmer NK, Elfering A, Jacobshagen N, Meier LL

Affiliation: Department of Psychology, University of Bern, Muesmattstrasse 45, 3000 Bern 9, Switzerland. martial.berset@psy.unibe.ch

Refers to the following texts of the Journal: 2006;32(1):5-11

2006;32(6):473-481

The following articles refer to this text: 2013;39(3):217-220;

2013;39(3):241-258

Key terms: body mass index; control; demand; effort-reward imbalance; job demand-control model; longitudinal study; social stressor; stress; weight

This article in PubMed: www.ncbi.nlm.nih.gov/pubmed/20835689

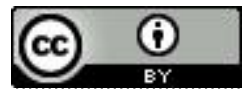




\title{
Does stress at work make you gain weight? A two-year longitudinal study
}

\author{
Martial Berset, PhD, ${ }^{1,2}$ Norbert K Semmer, PhD, ${ }^{1,2}$ Achim Elfering, PhD, ${ }^{1,2}$ Nicola Jacobshagen, PhD, 1, 2 \\ Laurenz L Meier, PhD 1,2
}

\begin{abstract}
Berset M, Semmer NK, Elfering A, Jacobshagen N, Meier LL. Does stress at work make you gain weight? A twoyear longitudinal study. Scand J Work Environ Health. 2011;37(1):45-53.

Objectives Research concerning the association between stress at work and body mass index (BMI) has mainly focused on two models (ie, job demand-control and effort-reward imbalance) as predictors and mostly been cross-sectional. The aim of our study is to extend previous research in two ways. First, social stressors - in the sense of social conflict and animosities at work - were included as an independent variable, arguing that they should be an especially promising predictor as they reflect a "social-evaluative threat". Second, a longitudinal design was employed with a two-year follow-up. In addition, the variables specified by the job demand-control model and the effort-reward imbalance model were assessed as well.
\end{abstract}

Methods Participants comprised 72 employees (52 men, 20 women) from a Swiss service provider. Multiple regression analyses were used to predict BMI two years later with social stressors, effort-reward imbalance, demands, control, and the interaction of demands and control. Baseline BMI was controlled so that the dependent variable reflects the change in BMI over two years.

Results Regression analyses revealed control and social stressors to be statistically significant predictors of follow-up BMI, while effort-reward imbalance was marginally significant.

Conclusions The results underscore the importance of social stressors and job control as predictors of stressrelated impaired health.

Key terms body mass index; control; demand; effort-reward imbalance; job demand-control model; social stressor.

This study focused on the impact of working conditions on the body mass index (BMI). Working conditions investigated include job demands and job control, which are derived from the job demand-control model, as well as effort-reward imbalance and social stressors.

The BMI is an important indicator of health. It is predictive of many health outcomes, such as diabetes (1) and cardiovascular disease $(2,3)$. In addition, it is an important driver of costs in the workplace through direct medical costs as well as indirect costs, such as absenteeism or workplace injuries (4). Given the importance of BMI for individual health and organizational costs, it seems crucial to identify variables that predict BMI and to understand mediating mechanisms linking stress at work and body weight. Knowing these variables can increase our understanding of the development of diseases that are related to body weight, and it can help to develop preventive measures.
Stress at work has repeatedly been considered a possible factor in the development of obesity $(5,6)$. Although we do not specifically examine the mechanisms linking stress at work and BMI in our study, we will briefly sketch the most important ones in order to explain the rationale behind our work.

One way in which stress can be transferred into a higher body weight is via the hormone cortisol, which is an important hormone in the regulation of the human stress response (7). Cortisol leads to an accumulation of fat in abdominal tissue and inhibits sex and growth hormone secretion, which would counteract this accumulation (5). Therefore, being exposed to stress should lead to an accumulation of fat via elevated cortisol levels.

A further mediating mechanism refers to changes in eating behavior. Eating may alleviate feelings of stress by making one feel better (8). Consequently, scales on coping with stress often include items like "eating more"

1 Swiss National Center of Competence in Research on “Affective Sciences”, Geneva, Switzerland
2 Department of Psychology, University of Bern, Bern, Switzerland

Correspondence to: Martial Berset, Department of Psychology, University of Bern, Muesmattstrasse 45, 3000 Bern 9, Switzerland. [E-mail: martial.berset@psy.unibe.ch]. 
(9). The same applies to increased alcohol consumption (10). Tsutsumi et al (11) not only found an association of job strain with higher consumption of alcohol but also with lower consumption of vegetables. Furthermore, Hellerstedt \& Jeffery (12) found that job demands were associated with higher fat intake among American men. Such unhealthy eating and drinking behavior is likely to be connected to stress because stress tends to weaken self-regulatory capacity (13). To the extent that eating healthy (or refraining from over-eating) requires selfcontrol, people may eat more and less healthy when stressed.

Besides food intake, physical activity is an important factor that influences weight. Exercising, however, also requires self-control, which tends to suffer under stress. Therefore, people should tend to exercise less when stressed, a situation which has, indeed, been found (14).

Impaired sleep may be a further mechanism how stress at work affects body weight. It has, for example, been found that short sleep duration is associated with a higher BMI $(15,16)$. An important cause of impaired sleep is stress (17). Therefore, it is plausible to assume that impaired sleep is a mediating mechanism between stress at work and body weight.

\section{Stress at work and body mass index}

Empirical studies investigating the association between stress at work and BMI have mainly concentrated on two models of stress: the job demand-control (18) and the effort-reward imbalance (19) models. We will briefly discuss pertinent research concerning these two models and BMI and present arguments why incorporating social stressors should be promising when trying to predict BMI.

\section{The job demand-control model and BMI}

The job demand-control model postulates an interaction between job demands and control. According to this model, job control should help employees to cope with the demands and thus attenuate their effects; conversely, the combination of high demands and low control implies a "high-strain" job, which should be experienced as especially stressful. Although an association between high strain and BMI seems plausible theoretically, this association has not been substantiated empirically so far. Overgaard et al (20) reviewed ten cross-sectional studies investigating the association between body weight and the variables specified by the job demand-control model. They concluded that the literature is not supportive of such an association. This conclusion holds for high-strain jobs as well as for the constituent variables (demands, control). The review by Siegrist \& Rödel (21) draws a similar conclusion.
However, if only prospective studies in this review (21) are considered, the job demand-control model receives some support in four out of six studies, although, for the most part, only main effects of either demands or control emerged as significant predictors.

\section{The effort-reward imbalance model and BMI}

The effort-reward imbalance model (19) suggests that a perceived imbalance between the effort invested in one's work and the rewards received (such as money, career opportunities, support) induces increased susceptibility to illness (22). This model has also been investigated with regard to BMI, although much less than the job demandcontrol model. Kivimäki et al (23) found a positive association between effort-reward imbalance and BMI in a prospective study. Kouvonen et al (24) found similar results in a cross-sectional study. In contrast Vrijkotte et al (25) could not show any association between effortreward imbalance and BMI in a cross-sectional analysis. Thus, there is weak support for an association between effort-reward imbalance and BMI, but the number of studies is still too small to draw firm conclusions.

\section{Social stressors}

One reason for the lack of empirical evidence for an association between work stress and BMI so far might lie in the small range of predictors that have been investigated. Specifically, we argue that social stressors, which have largely been neglected in this context, should be especially promising. Social stressors, as described by Dormann \& Zapf (26) relate to "social animosities, conflicts with co-workers and supervisors, unfair behavior, and a negative group climate". Social stressors are a direct threat to an individual's need to belong, which is related to negative affect (27) and selfesteem (28). Therefore, social stressors are supposed to be experienced as being very unpleasant.

Social stressors have, indeed, been shown to predict strain $(26,29)$. Further results supporting the importance of social stressors come from a meta-analysis by Dickerson \& Kemeny (30). They showed that social-evaluative elements ("social-evaluative threat") emerged as one of two stressful characteristics of tasks capable of eliciting cortisol responses (the second one being uncontrollability). Considering the importance of cortisol with respect to body weight, such results, therefore, strongly suggest that social stressors should not be neglected in this area. To our knowledge, however, there is only one study (6) that has investigated the relationship between social aspects (ie, conflicts) of the workplace and BMI and which, surprisingly, found no association. However, in that study the measure of conflict was dichotomized, using a rather low threshold, which resulted in almost 
half of the participants being considered as being exposed to social conflict, treating people with rather low levels of conflict on the same level as people with rather high levels of conflict. Assessing social stressors with a continuous variable may well lead to different results. In any case, with only one study, it would be premature to conclude that social stressors are not predictive of BMI. Altogether, theoretical considerations and empirical evidence for the role of social stressors in predicting strain (including cortisol) responses strongly suggest social stressors to be promising for predicting weight change.

With this study, we would like to contribute to the research on BMI in several ways. First, we want to assess the predictive power of the two most prominent models in occupational stress research, namely those of job demand-control and effort-reward imbalance. Second, we want to extend previous research by investigating the predictive power of social stressors. Third, we want to strengthen the explanatory value of our results by employing a longitudinal design with a time lag of two years. By controlling for baseline BMI, the remaining variance reflects the relative change in BMI during these two years, which we then try to predict with baseline working conditions. Testing all predictors in a single model would imply an unfortunate ratio of predictors to participants and problems with multicolinearity, since the predictors are considerably correlated (see table 1). Therefore, we tested each model separately and then entered those predictors that were significant in any of these three analyses into a final model.

\section{Hypotheses}

As argued, it is theoretically plausible to assume associations between demands, control, and their interaction with BMI, with empirical evidence being weak in crosssectional studies, but somewhat stronger in longitudinal studies. Confirming evidence relates mostly to individual variables of the model, that is, demands and control. These findings are in line with the evidence on the job demand-control model in general (31). We, therefore, expect BMI at time 2 to be associated positively with demands at time 1 (hypothesis 1.1) and negatively with control at time 1 (hypothesis 1.2).

Theoretically, an effect of effort-reward imbalance on body weight seems very plausible as well. Empirically, there is some support for this association, but it is based on only few studies so far. Given the trend in the few existing studies, and the strong support for the model in general (32), we expect a positive association between effort-reward imbalance at time 1 and BMI at time 2 (hypothesis 2).

Concerning social stressors, there is not much evidence with respect to BMI. Based on our theoretical arguments and the empirical evidence for the importance of social stressors in general, we expect a positive association of social stressors at time 1 with BMI at time 2 (hypothesis 3).

\section{Methods}

\section{Participants and design}

Employees from three departments of a large Swiss service provider were asked to fill in a questionnaire at two times (2003 and 2005), with a time-lag of two years. The study was presented at general meetings of the departments, with about 245 individuals present. A total of 147 participants filled out the first questionnaire, corresponding to a response rate of approximatively $65 \%$. Two years later, those 114 participants who were still working in the same organization were asked to participate again. Of those, 76 (66\%: 56 men, 20 women) agreed and filled out the follow-up questionnaire. The sample includes bluecollar workers (eg, people transporting goods) and whitecollar workers (eg, secretaries, accountants). The mean age was 41.89 years [standard deviation $(\mathrm{SD})=9.13$ ] Due to missing data and list-wise deletion, the sample for the various analyses varies between $\mathrm{N}=68$ and $\mathrm{N}=72$.

\section{Measures}

Job demand-control model. Karasek (18) conceptualized job demands rather broadly, including "workload demands, conflicts or other stressors" (p287). We follow this tradition of a broader definition and used a short self-report version of the Instrument for Stress Oriented Task Analysis (ISTA) (33) to measure demands. It assesses five task stressors with four items each. Time pressure (eg, "How often do you have to work faster than normal in order to complete your work?"), concentration demands (eg, "How often must you remember many things simultaneously?"), uncertainty (eg, "How often do you receive unclear instructions?"), and work interruptions (eg, "How often are you interrupted by other colleagues during the course of your work activity?") were assessed with a 5-point Likert format, reflecting either intensity or frequency. The format of the fifth scale, performance constraints, was slightly different: two workplaces with opposing characteristics were described (for example "must spend a lot of time in order to get information and/or materials to pursue his/her work activity" versus "always has the necessary information and/or materials at his/her disposal"); participants had to rate, on a 5-point Likert scale, to which of those two workplaces their own is most similar.

To estimate the reliability of such a composite of scales consisting of subscales that are inter-correlated 
but do not represent a homogeneous construct, a composite score proposed by Nunnally \& Bernstein (34) is appropriate. The composite score was $r_{Y Y}=0.85$.

Job control was measured with a 6 -item scale that covers time control (eg, "To what degree is it possible for you to set your own working pace?") and method control (eg, "Can you decide on which way to carry out your work?") with 3 items each [5-point Likert scale, ISTA (33)]. Internal consistency (Cronbach's alpha) was $\alpha=0.91$.

Effort-reward imbalance. Effort-reward imbalance was measured with a 6-item scale by van Yperen (35) adapted by Jansen (36). Van Yperen (35) calls the scale "exchange relationship with the organization", which encompasses the idea of equity between an employee's investments and the rewards he or she gets. In contrast to the instrument by Siegrist (37), this scale does not calculate a ratio between efforts and reward, but directly envelopes the imbalance of efforts and rewards in single items. Examples are: "The rewards you receive are not proportional to your investments" and "You give a great deal of time and attention to the organization, but get very little appreciation". Cronbach's alpha was $\alpha=0.92$.

Social stressors. Social stressors were measured with an 8-item scale developed by Frese \& Zapf (38). The items had to be rated on a 5-point Likert scale ranging from "strongly disagree" to "strongly agree". The items are: (i) "My supervisor always assigns the pleasant tasks to particular people", (ii) "One has to pay for the mistakes of others", (iii) "With some colleagues there is often conflict", (iv) "I have to work with people who can't take a joke", (v) "My supervisor pushes all the time", (vi) "When an error occurs, the supervisor always blames us but never himself", (vii) "Around here, one gets reprimanded even for little things", (viii) "Some colleagues interrupt the regular work rhythm repeatedly" (39). Cronbach's alpha was $\alpha=0.75$.

Body mass index and control variables. Self-reported data provided weight and height of the participants for the calculation of BMI. Since the BMI is dependent on age and gender (40), these two variables were entered as control variables into the analyses. Social class has also been found to be inversely related to being overweight (41). We, therefore, controlled for educational attainment, which can be considered a proxy for social class. We asked individuals about their highest graduation level achieved and clustered the answers into three groups: basic school graduation, apprenticeship, and higher education. Because this is an ordinal variable, we used Spearman's Rho to calculate correlations and built dummy variables to control for educational attainment in regression analyses.

\section{Statistical analysis}

First, correlations between all predictors, controls, and the criterion were calculated. Second, to test each model individually, three prospective multiple regression analyses were computed. The control variables and baseline BMI (time 1) were entered in the first step, the predictors specified by the respective stress model (job demand-control, effort-reward imbalance, social stressors), measured at the baseline, were entered in the second step. With respect to the job demand-control model, the interaction term followed in step 3. The variables for calculating the interaction were centered at their mean. Entering baseline BMI as a control variable had the consequence that the individual stability of the body weight was partialed out of the dependent variable. Therefore, the dependent variable then represented the deviation of BMI from the value that was to be expected based on its baseline value.

In a second step, a trimmed model, consisting of the predictors that were significant in any of the initial analyses, was calculated.

\section{Results}

\section{Correlations}

Means, SD, and intercorrelations are shown in table 1. Mean BMI did not change from time 1 to time 2. As expected, BMI at baseline correlated very highly with BMI at follow-up ( $r=0.92, P<0.01)$, indicating considerable stability. Gender correlated negatively with BMI at baseline $(r=-0.33, P<0.01)$ and follow-up $(r=-0.25$, $P<0.05)$, indicating that men had a higher BMI than women. No association was found for age.

Associations of the stressors with follow-up BMI were positive and significant throughout. Demands $(r=0.31, P<0.05)$ and social stressors $(\mathrm{r}=0.24, P<0.05)$ were also correlated positively with baseline BMI; however, effort-reward imbalance was not. Correlations between stressors and BMI were higher for BMI two years later than at baseline, possibly indicating that the influence of stress on body weight is a delayed one.

Women experienced less job demands $(r=-0.29$, $P<0.05)$ and less job control $(\mathrm{r}=-0.31, P<0.05)$ than men. Educational attainment correlated positively with demands and control $(r=0.29, P<0.05 ; r=0.36$, $P<0.01)$ but not with BMI. Intercorrelations between the different stressors were positive. Job control was negatively correlated with effort-reward imbalance but not associated with BMI. 


\section{Regression analysis}

Tables 2-4 show the results for the regression analysis pertaining to each stress model. Baseline BMI was by far the strongest predictor of BMI at follow-up. Concerning the variables of the job demand-control model, only control emerged as a significant predictor, and the coefficient was negative, as expected (table 2). Thus, control, while not correlated with baseline and followup BMI, did predict relative change in BMI. Neither the main effect for demands nor the interaction between demands and control were significant predictors of follow-up BMI.

Effort-reward imbalance did not predict BMI to a statistically significant amount, although it was marginally significant ( $\mathrm{P}=0.08$; table 3 ). Social stressors did, however, emerge as a significant predictor (table 4).

Since control and social stressors emerged as significant predictors of BMI when the underlying models were tested individually, we ran a further regression analysis in which we entered control and social stressors in step 2, after demographics and baseline BMI. As shown in table 5 , both could explain a significant amount of variance over and above baseline BMI.

\section{Discussion}

The most important result of these analyses is that social stressors and job control predicted relative change in BMI over a period of two years. We expected social stressors to be especially important because they imply being offended and treated with disrespect. Thus, they represent a threat to one's self-worth. Feeling accepted by others is a basic human need; therefore, a social situation involving negative evaluations and offending treatment are likely to be experienced as highly stressful (42). As outlined in the introduction, being stressed can then lead to a gain in weight through several pathways,

Table 1. Descriptive statistics and correlations among the study variables. All are Pearson correlation coefficients except for correlations with educational attainment, which are Spearman's Rho; $\mathrm{N}=68$. [SD=standard deviation; $\mathrm{BMI}=$ body mass index; ERI=effort-reward imbalance.]

\begin{tabular}{|c|c|c|c|c|c|c|c|c|c|c|}
\hline Variables & Mean & SD & $\begin{array}{l}\text { BMI } \\
\text { time } 1\end{array}$ & $\begin{array}{l}\text { BMI } \\
\text { time } 2\end{array}$ & $\begin{array}{l}\text { Demands } \\
\text { time } 1\end{array}$ & $\begin{array}{l}\text { Control } \\
\text { time } 1\end{array}$ & $\begin{array}{l}\text { ERI } \\
\text { time } 1\end{array}$ & $\begin{array}{c}\text { Social stressors } \\
\text { time } 1\end{array}$ & Age & Gender a \\
\hline BMI time 1 & 24.45 & 3.20 & . & . & - & . & . & . & . & . \\
\hline BMI time 2 & 24.45 & 3.14 & $0.92^{b}$ & . & $\cdot$ & . & . & . & . & . \\
\hline Demands time 1 & 3.07 & 0.44 & $0.31^{b}$ & $0.36^{b}$ & . & . & . & $\cdot$ & . & . \\
\hline Control time 1 & 3.51 & 1.00 & 0.17 & 0.01 & 0.04 & . & . & $\cdot$ & . & . \\
\hline ERI time 1 & 3.25 & 1.29 & 0.18 & $0.25^{c}$ & $0.48^{b}$ & $-0.24 c$ & . & . & . & . \\
\hline Social stressors time 1 & 2.05 & 0.56 & $0.24^{c}$ & $0.35 b$ & $0.41^{b}$ & $-0.21 d$ & $0.60^{b}$ & . & . & . \\
\hline Age & 41.89 & 9.13 & 0.06 & 0.02 & 0.11 & 0.08 & -0.17 & -0.07 & . & . \\
\hline Gender a & 0.28 & 0.45 & $-0.33^{b}$ & $-0.25^{c}$ & $-0.29 c$ & $-0.31^{c}$ & -0.16 & -0.19 & -0.17 & \\
\hline Educational attainment & . & . & 0.06 & -0.01 & $0.29 c$ & $0.36^{b}$ & -0.18 & -0.07 & 0.01 & $-0.24 c$ \\
\hline
\end{tabular}

a $0=$ male, $1=$ female. Listwise deletion.

b $P<0.01$ (2-tailed).

c $\mathrm{P}<0.05$ (2-tailed)

d $P<0.10$ (2-tailed).

Table 2. Summary of multiple regression analysis for the job demand-control model predicting follow-up body mass index (BMI); $\mathrm{N}=68$. $[B=$ unstandardized regression coefficient. $S E B=$ standard error of unstandardized regression coefficient. $\beta=$ standardized regression coefficient. $\Delta R^{2}=$ change in explained variance. $R^{2}=$ explained variance.]

\begin{tabular}{|c|c|c|c|c|c|}
\hline Variables & B (final) & SE B & $\beta$ (final) & $\Delta \mathrm{R}^{2}$ & $\mathrm{R}^{2}$ \\
\hline Step 1 & . & $\cdot$ & . & . & 0.85 \\
\hline BMI time 1 & 0.94 & 0.05 & $0.94^{\text {a }}$ & . & . \\
\hline Education dummy I & -0.61 & 0.53 & -0.06 & . & . \\
\hline Education dummy II & 0.29 & 0.36 & 0.04 & . & . \\
\hline Age & 0.00 & 0.02 & -0.01 & . & . \\
\hline Gender b & 0.42 & 0.38 & 0.06 & . & . \\
\hline Step 2 & . & $\cdot$ & . & $0.02^{a}$ & 0.87 \\
\hline $\begin{array}{l}\text { Demands time } 1 \\
\text { Control time } 1\end{array}$ & $\begin{array}{r}0.47 \\
-0.45\end{array}$ & $\begin{array}{l}0.37 \\
0.16\end{array}$ & $\begin{array}{r}0.07 \\
-0.14 a\end{array}$ & . & . \\
\hline Step 3 & $\cdot$ & . & $\cdot$ & 0.00 & 0.87 \\
\hline Demands $\times$ control time 1 & -0.28 & 0.34 & -0.04 & . & . \\
\hline
\end{tabular}

a $P<0.01$ (2-tailed)

b $0=$ male, $1=$ female 
Table 3. Summary of multiple regression analysis for the effort-rewards imbalance model predicting follow-up body mass index (BMI); $\mathrm{N}=70$. [ $\mathrm{B}=$ unstandardized regression coefficient. $\mathrm{SE} B=$ standard error of unstandardized regression coefficient. $\beta=$ standardized regression coefficient. $\Delta R^{2}=$ change in explained variance. $R^{2}=$ explained variance.]

\begin{tabular}{|c|c|c|c|c|c|}
\hline Variables & B (final) & SE B & $\beta$ (final) & $\Delta \mathrm{R}^{2}$ & $\mathrm{R}^{2}$ \\
\hline Step 1 & & & & . & 0.85 \\
\hline BMl time 1 & 0.93 & 0.05 & $0.94^{\text {a }}$ & . & . \\
\hline Education dummy I & -0.71 & 0.55 & -0.06 & . & . \\
\hline Education dummy II & 0.26 & 0.36 & 0.04 & . & . \\
\hline Age & 0.00 & 0.02 & 0.00 & . & . \\
\hline Gender b & 0.70 & 0.37 & $0.10^{c}$ & . & . \\
\hline Step 2 & & & & $0.01^{c}$ & 0.86 \\
\hline Effort-reward imbalance time 1 & 0.22 & 0.12 & $0.09^{c}$ & . & . \\
\hline
\end{tabular}

a $P<0.01$ (2-tailed).

b $0=$ male, $1=$ female.

${ }^{c} P<0.10$ (2-tailed).

Table 4. Summary of multiple regression analysis with social stressors predicting follow-up body mass index (BMI); $N=70$. $[B=$ unstandardized regression coefficient. $S E B=$ standard error of unstandardized regression coefficient. $\beta=$ standardized regression coefficient. $\Delta R^{2}=$ change in explained variance. $R^{2}=$ explained variance.]

\begin{tabular}{|c|c|c|c|c|c|}
\hline Variables & B (final) & SE B & $\beta$ (final) & $\Delta \mathrm{R}^{2}$ & $\mathrm{R}^{2}$ \\
\hline Step 1 & . & & . & & 0.85 \\
\hline BMI time 1 & 0.92 & 0.05 & 0.93 & . & . \\
\hline Education dummy I & -0.80 & 0.52 & -0.07 & . & r \\
\hline Education dummy II & 0.14 & 0.33 & 0.02 & . & . \\
\hline Age & 0.00 & 0.02 & -0.01 & . & . \\
\hline Gender ${ }^{a}$ & 0.71 & 0.35 & $0.10^{b}$ & . & . \\
\hline Step 2 & . & & . & $0.02^{c}$ & 0.87 \\
\hline Social stressors time 1 & 0.75 & 0.26 & $0.14^{\mathrm{c}}$ & . & . \\
\hline
\end{tabular}

a $0=$ male, $1=$ female.

b $P<0.05$ (2-tailed).

c $P<0.01$ (2-tailed).

such as heightened cortisol levels, changed eating patterns, impaired sleep etc.

In our first hypothesis, we expected main effects for demands and control. Only control showed a significant effect in the regression analyses, however. Several aspects about these results are noteworthy. First, in line with previous research, no interaction was found. Second, regarding the two variables specified by the model, existing research suggests that the effects of control are more consistent than those of demands (43). Our results confirm this picture. Interestingly, control was significant in the multiple regression analysis only. Detailed analyses revealed that it became significant once the baseline value of BMI was controlled. Thus, while not associated with BMI as such, control is associated with (relative) change in BMI.

With respect to our second hypothesis, the weak prediction by effort-reward imbalance is difficult to explain. Effort-reward imbalance indicates a lack of reciprocity and fairness. As such, it is conceptually rather close to social stressors, and likely to reflect a "social-evaluative threat", at least to some degree. The conceptual overlap can be seen in the correlation between effort-reward imbalance and social stressors, which is rather high $(\mathrm{r}=0.60)$. There is one difference, however, that may be important: social stressors refer to events that are characterized by tension, offense, conflict, neglect, lack of appreciation, etc. Social stressors, therefore, represent experiences where many of the mechanisms involved in weight issues come into play (eg, increases in cortisol, coping by changes in eating behavior, and breakdown of self-control). By contrast, effort-reward imbalance may not primarily reflect specific events but rather a more general evaluation of one's work situation that results when reflecting about one's work. However, such explanations must remain speculative at this point. At the same time, it should be mentioned that our sample size is not very large. Effort-reward imbalance showing a marginally significant effect may therefore indicate a lack of power rather than a failure of effort-reward imbalance to predict BMI, and a significant effect may well occur with larger samples (44). Thus, while our results support an association between BMI and social stressors as well as control, the effects of effort-reward imbalance should not be dismissed based on these results. 
Table 5. Summary of multiple regression analysis with control and social stressors predicting follow-up body mass index (BMI) (trimmed model); $N=70$. [B=unstandardized regression coefficient. $S E B=$ standard error of unstandardized regression coefficient. $\beta=$ standardized regression coefficient. $\Delta R^{2}=$ change in explained variance. $R^{2}=$ explained variance.]

\begin{tabular}{|c|c|c|c|c|c|}
\hline Variables & B (final) & SE B & $\beta$ (final) & $\Delta \mathrm{R}^{2}$ & $\mathrm{R}^{2}$ \\
\hline Step 1 & . & 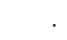 & . & . & 0.85 \\
\hline BMI time 1 & 0.93 & 0.05 & $0.94^{a}$ & . & . \\
\hline Education dummy I & -0.70 & 0.51 & -0.06 & . & . \\
\hline Education dummy II & 0.33 & 0.34 & 0.05 & . & . \\
\hline Age & 0.00 & 0.02 & -0.01 & . & . \\
\hline Gender b & 0.52 & 0.35 & 0.08 & . & . \\
\hline Step 2 & & & & $0.03^{a}$ & 0.88 \\
\hline Control time 1 & -0.33 & 0.16 & $-0.11^{c}$ & . & . \\
\hline Social stressors time 1 & 0.60 & 0.27 & $0.11^{\mathrm{c}}$ & . & . \\
\hline
\end{tabular}

a $\mathrm{P}<0.01$ (2-tailed).

${ }^{b} 0=$ male, $1=$ female.

c $\mathrm{P}<0.05$ (2-tailed).

Referring to our third hypothesis, one could argue that the $2 \%$ variance explained by social stressors (see table 4) is sparse. It is noteworthy, however, that this effect occurs despite a considerable stability in BMI. With a standardized regression coefficient of 0.92 , there is not much variance left to be explained by other variables. Thus, the effect of social stressors seems quite remarkable. The practical relevance of social stressors is reflected in the unstandardized regression coefficient of 0.75 (see table 4). This implies that an increase in one point on the 5-point social stressors scale is associated with an increase in predicted BMI of 0.75 points two years later. Given that the difference of one point in BMI is related to a $4-5 \%$ increase in risk of coronary heart disease mortality (45), this effect of social stressors on BMI is not trivial. Note that this effect is obtained with social stressors at work, which constitutes only a subset of social stressors people experience in life.

We controlled for age, gender, and education, the last of which we used as a proxy for social class. Nevertheless, one can never rule out that the effects found are due to other confounding variables that we did not measure. However, such confounding factors would in all likelihood have influenced BMI already at baseline; since that variable is controlled for in our longitudinal study, we are confident that social stressors and control are, indeed, predictors of relative change in BMI.

It also seems conceivable that social stressors not only predict BMI, but that BMI, at the same time, leads to more social stressors. For example, it may be that overweight individuals are more frequent victims of bullying. This would then suggest a negative spiral, in which weight and stress reinforce each other. We tested this reverse causation hypothesis, but BMI was not predictive of social stressors two years later, however (more detailed results can be obtained from the first author).

Individuals may react differently with respect to their eating behavior when suffering from chronic stress
(8). Assuming that these differences accumulate under chronic stress, they should also be reflected in differences in baseline BMI (2). As a consequence, we tested if the baseline BMI interacts with the working conditions in predicting follow-up BMI. There was a significant interaction between baseline BMI and job control. Individuals high in baseline BMI benefited from job control as they lost weight, whereas there was no change in BMI for individuals low in baseline BMI. No interactions were found between baseline BMI and job stressors. Therefore, there is some indication for differential effects of working conditions on body weight, but the evidence is far from conclusive.

\section{Strengths and limitations}

This study has two strong points. First, several different aspects of working conditions were investigated within the same study. Second, the longitudinal design makes a stronger case for a causal role of social stressors than a cross-sectional design would have permitted.

A limitation of our study is the rather small sample size, implying limited power. The low power makes the effect of social stressors even more remarkable, but the effect of effort-reward imbalance may have been underestimated because of the small sample size. Another consequence of the small sample size is a somewhat limited generalizability of our results. Further research and replication is, therefore, needed.

Another limitation is the use of self-reported data for weight and height. This might have induced a bias, due to social desirability. However, a study by Donaldson \& Grant-Vallone (46) suggested that self-reported data of height and weight are quite accurate. Furthermore, Boström \& Diderichsen (47) argue that self-reported measures of BMI should have little effect on analyses, as long as BMI is used as a continuous and not a categorical variable. To the extent that a bias does nevertheless 
exist, it is likely that this is a bias towards the mean, in that overweight people tend to underestimate and underweight people to overestimate their weight (48). This would result in effects being underestimated, rather than overestimated, as the bias would imply a restricted range of values. We, therefore, are quite confident that our self-report measure did not result in a serious distortion of results.

\section{Concluding remarks}

According to our results, social stressors and job control are important predictors of BMI. They should, therefore, receive more attention in future research. Besides replication, future research should also focus more on the mechanisms involved, such as metabolic mechanisms, as for example the role of cortisol, changes in eating behavior, physical activity, and disturbed sleep. Furthermore, future research should include social stressors in private life in addition to social stressors at work.

\section{References}

1. Resnick HE, Valsania P, Halter JB, Lin X. Differential effects of BMI on diabetes risk among black and white Americans. Diabetes Care. 1998;21(11):1828-35.

2. Kivimäki M, Head J, Ferrie JE, Shipley MJ, Brunner E, Vahtera J, et al. Work stress, weight gain and weight loss: evidence for bidirectional effects of job strain on body mass index in the Whitehall II study. Int J Obes. 2006;30(6):982-7.

3. Yusuf S, Hawken S, Ounpuu S, Bautista L, Franzosi MG, Commerford P, et al. Obesity and the risk of myocardial infarction in 27000 participants from 52 countries: a casecontrol study. Lancet. 2005;366(9497):1640-9.

4. Schmier JK, Jones ML, Halpern MT. Cost of obesity in the workplace. Scand J Work, Environ Health. 2006;32(1):5-11.

5. Björntorp P. Do stress reactions cause abdominal obesity and comorbidities? Obes Rev. 2001;2(2):73-86.

6. Hannerz H, Albertsen K, Nielsen ML, Tüchsen F, Burr $\mathrm{H}$. Occupational factors and 5-year weight change among men in a Danish national cohort. Health Psychol. 2004 May;23(3):283-8.

7. Lovallo WR. Stress \& health: biological and psychological interactions. Thousand Oaks (CA): Sage Publications Inc; 2005.

8. Greeno CG, Wing RR. Stress-induced eating. Psychol Bull. 1994;115(3):444.

9. Endler NS, Parker JDA. Multidimensional assessment of coping: A critical evaluation. J Pers Soc Psychol. 1990;58(5):844-54.

10. Carver CS, Scheier MF, Weintraub JK. Assessing coping strategies: A theoretically based approach. J Pers Soc Psychol. 1989;56(2):267-83.

11. Tsutsumi A, Kayaba K, Yoshimura M, Sawada M, Ishikawa
S, Sakai K, et al. Association between job characteristics and health behaviors in Japanese rural workers. Int J Behav Med. 2003;10(2):125-42.

12. Hellerstedt WL, Jeffery RW. The association of job strain and health behaviours in men and women. Int J Epidemiol. 1997;26(3):575-83.

13. Baumeister RF, Heatherton TF. Self-Regulation Failure: An Overview. Psychol Inq. 1996;7(1):1-15.

14. Sonnentag S, Jelden S. Job stressors and the pursuit of sport activities: A day-level perspective. J Occup Health Psychol. 2009; 14(2):165-81.

15. Taheri S, Lin L, Austin D, Young T, Mignot E. Short sleep duration is associated with reduced leptin, elevated ghrelin, and increased body mass index. PLoS Med. 2004;1(3):210.

16. Chaput JP, Després JP, Bouchard C, Tremblay A. The association between sleep duration and weight gain in adults: a 6-year prospective study from the Quebec Family Study. Sleep. 2008;31(4):517.

17. Åkerstedt T, Nilsson PM, Kecklund G. Sleep and recovery. In: Sonnentag S, Perrewé PL, Ganster D, editors. Current perspectives on job-stress recovery. Oxford: Elsevier; 2009:205-47.

18. Karasek Jr RA. Job demands, job decision latitude, and mental strain: Implications for job redesign. Adm Sci Q. 1979:285-308.

19. Siegrist J. Effort-reward imbalance at work and health. In: Perrewé PL, Ganster DC, editors. Historical and current perspectives on stress and health; 2002:261-91.

20. Overgaard D, Gyntelberg F, Heitmann BL. Psychological workload and body weight: is there an association? A review of the literature. Occup Med (Lond). 2004;54(1):35-41.

21. Siegrist J, Rödel A. Work stress and health risk behavior. Scand J Work Environ Health. 2006;32(6):473-81.

22. Siegrist J, Starke D, Chandola T, Godin I, Marmot M, Niedhammer I, et al. The measurement of effort-reward imbalance at work: European comparisons. Soc Sci Med. 2004;58(8):1483-99.

23. Kivimäki M, Leino-Arjas $\mathrm{P}$, Luukkonen R, Riihimäki H, Vahtera J, Kirjonen J. Work stress and risk of cardiovascular mortality: prospective cohort study of industrial employees. $\mathrm{Br}$ Med J. 2002;325(7369):857-61.

24. Kouvonen A, Kivimäki M, Cox SJ, Cox T, Vahtera J. Relationship between work stress and body mass index among 45,810 female and male employees. Psychosom Med. 2005;67(4):577-83.

25. Vrijkotte TGM, van Doornen LJP, de Geus EJC. Work stress and metabolic and hemostatic risk factors. Psychosom Med. 1999;61(6):796-805.

26. Dormann C, Zapf D. Social stressors at work, irritation, and depressive symptoms: Accounting for unmeasured third variables in a multi-wave study. Journal of Occupational and Organizational Psychology. 2002;75(1):33-58.

27. Baumeister RF, Leary MR. The need to belong: Desire for interpersonal attachments as a fundamental human motivation. Psychol Bull. 1995;117:497-529.

28. Semmer NK, Jacobshagen N, Meier LL, Elfering A. 
Occupational stress research: The "stress-as-offence-toself" perspective. In: Houdmont J and McIntyre S, editors. Occupational health psychology: European perspectives on research, education and practice. Nottingham (UK): Nottingham University Press; 2007.

29. Grebner S, Elfering A, Semmer NK. Social stressors at work predict well-being and health beyond negative affectivity, social support, and job content. Paper presented at the Work, Stress, \& Health 2006 Conference, March 2-4, 2006. (Miami) Florida: American Psychological Association; 2006.

30. Dickerson SS, Kemeny ME. Acute stressors and cortisol responses: A theoretical integration and synthesis of laboratory research. Psychol Bull. 2004;130(3):355-91.

31. Terry DJ, Jimmieson NL. Work control and employee well-being: A decade review. In: Robertson I, Cooper CL, editors. International review of industrial and organizational psychology (volume 14). Chichester, UK: Wiley and Sons; 1999. p95-148.

32. Van Vegchel N, de Jonge J, Bosma H, Schaufeli W. Reviewing the effort-reward imbalance model: drawing up the balance of 45 empirical studies. Soc Sci Med. 2005;60(5):1117-31.

33. Semmer NK, Zapf D, Dunckel H. Assessing stress at work: A framework and an instrument. In: Svane O, Johansen C, editors. Work and health: Scientific basis of progress in the working environment. Luxembourg: Office for Official Publications of the European Communities; 1995. p105-13.

34. Nunnally JC, Bernstein IC. Psychometric theory. New York: McGraw-Hill; 1994.

35. Van Yperen NW. Communal Orientation and the Burnout Syndrome Among Nurses: A Replication and Extension. J Appl Soc Psychol. 1996;26(4):338-54.

36. Janssen O. Job demands, perceptions of effort-reward fairness and innovative work behaviour. Journal of Occupational and Organizational Psychology. 2000;73(3):287-302.

37. Siegrist J, Starke D, Chandola T, Godin I, Marmot M, Niedhammer I, et al. The measurement of effort-reward imbalance at work: European comparisons. Social Science \& Medicine. 2004;58(8):1483-99.

38. Frese M, Zapf D. Eine Skala zur Erfassung von Sozialen Stressoren am Arbeitsplatz [A scale to measure social stressors at work]. Z Arbeitswiss. 1987;3:134-41.
39. Dormann C, Zapf D. Social stressors at work, irritation, and depressive symptoms: Accounting for unmeasured third variables in a multi-wave study. J Occup Organ Psychol. 2002;75:33-58.

40. Jordan D, Kuntsche S, Gmel G. Übergewicht bei Erwachsenen in der Schweiz: Aspekte einer multifaktoriellen Problematik. Ergebnisse der schweizerischen Gesundheitsbefragung 2002 [Overweight in adults in Switzerland]. Neuchâtel: Bundesamt für Statistik; 2007.

41. Brunner EJ, Marmot MG, Nanchahal K, Shipley MJ, Stansfeld SA, Juneja M, et al. Social inequality in coronary risk: central obesity and the metabolic syndrome. Evidence from the Whitehall II study. Diabetologia. 1997;40(11):1341-9.

42. Semmer NK, McGrath JE, Beehr TA. Conceptual issues in research on stress and health. In: Cooper CL, editor. Handbook of stress medicine and health. Boca Raton, FL: CRC Press; 2005. p1-43.

43. Bosma H, Peter R, Siegrist J, Marmot M. Two alternative job stress models and the risk of coronary heart disease. Am Public Health Assoc; 1998. p68-74.

44. Maxwell SE. The persistence of underpowered studies in psychological research: Causes, consequences, and remedies. Psychol Methods. 2003;9(2):147-63.

45. Jousilahti P, Tuomilehto J, Vartiainen E, Pekkanen J, Puska P. Body Weight, Cardiovascular Risk Factors, and Coronary Mortality 15-Year Follow-up of Middle-aged Men and Women in Eastern Finland. Circulation. 1996;93(7):1372-9.

46. Donaldson SI, Grant-Vallone EJ. Understanding self-report bias in organizational behavior research. J Bus Psychol. 2002;17(2):245-60.

47. Boström G, Diderichsen F. Socioeconomic differentials in misclassification of height, weight and body mass index based on questionnaire data. Int J Epidemiol. 1997;26(4):860-6.

48. Roberts RJ. Can self-reported data accurately describe the prevalence of overweight? Public Health. 1995;109(4):275-84.

Received for publication: 26 February 2010 